\title{
Assessment of the implementation of cross-border balancing trade between Belgium and the Netherlands
}

\author{
L. Vandezande, M. Saguan, L. Meeus, J-M. Glachant, R. Belmans
}

\begin{abstract}
Balancing services in Belgium and the Netherlands are procured and activated locally so far. However, the implementation of cross-border balancing trade between both countries is expected to entail significant benefits. The assessment in this paper illustrates that the implementation of a cross-border balancing market between Belgium and the Netherlands is a lucrative and achievable goal that does not entail unrealistic or overly expensive preconditions. Significant cost reductions could have occurred with cross-border balancing during the year 2008 - due to netting and cross-border procurement of relatively cheaper services. Restrictions imposed on cross-border balancing due to cross-border capacity constraints would have been rather small.
\end{abstract}

\section{INTRODUCTION}

Since the launch of electricity sector liberalisation in the EU, The European Commission and the European energy regulating institutions have pursued - and continue to pursue - the creation of an Internal Electricity Market (IEM). Considerable effort has been put into integrating national electricity markets, prompting a number of successful regional initiatives, so far mainly focusing on the day-ahead and intra-day stage [1]. The implementation of balancing markets spanning national frontiers constitutes an important next step towards completing the IEM.

Often cited benefits of cross-border balancing trade include an improved market functioning and a more efficient deployment of energy resources. The intention of this paper is not to question these benefits but rather to obtain some basic insight into their extent as well as to identify potential costs and/or barriers associated with the implementation. Put it differently, this paper aims to verify whether the implementation of cross-border balancing is a lucrative and achievable goal without unrealistic or too costly preconditions. To this end, potential effects of enabling cross-border balancing between Belgium and the Netherlands - two adjacent countries whose electricity markets have been successfully integrated so far up to the day-ahead stage (cf. the Trilateral Market Coupling Initiative between the

L. Vandezande is with the Electrical Engineering Department, KULeuven, Belgium. (phone: +32-(0)16/321722; fax: +32-(0)16/321985; leen.vandezande@esat.kuleuven.be).

M. Saguan is with Groupe Réseaux - Jean Monnet, Paris XI (e-mail: marcelo.saguan@u-psud.fr).

L. Meeus is with the Electrical Engineering Department, KULeuven (e-mail: leonardo.meeus@esat.kuleuven.be).

J-M. Glachant is with groupe Réseaux Jean-Monnet, Paris XI (e-mail: jean-michel.glachant@wanadoo.fr).

R. Belmans is with the Electrical Engineering Department, KULeuven (e-mail: ronnie.belmans@esat.kuleuven.be). day-ahead power exchanges of France, Belgium and the Netherlands) - are assessed.

The paper is organised as follows. Section 2 briefly describes balancing markets in Belgium and the Netherlands and provides insight into the potential benefits of enabling cross-border trade between both. Section 3 sets out the way in which cross-border balancing should be optimally implemented. Section 4 introduces the dataset used and the pursued methodology. Section 5 discusses the main results. Section 6 draws conclusions with respect to the feasibility of implementing cross-border balancing between Belgium and the Netherlands.

\section{BALANCING MARKETS IN BELGIUM AND THE NETHERLANDS}

Balancing services in Belgium and the Netherlands are procured and activated locally so far. The exchange of services across borders is restricted to emergency cases and consequently rather exceptional.

The implementation of cross-border balancing trade between both countries is expected to entail significant gains. First, system imbalances in both countries often exhibit a different direction, implying they could partially or fully be cancelled out against each other. In 2008, system imbalances in both countries had opposite directions during $45.5 \%$ of all settlement periods ( $1 / 4$ hours). Furthermore, procurement costs of balancing services substantially differ between both countries. In 2008, marginal prices of balancing services in Belgium were on average significantly lower than in the Netherlands. Finally, interconnection capacity between both countries is mostly far from being fully used. In 2008, cross-border capacity was still available after day-ahead gate closure during $94.3 \%$ of time in the direction Belgium to the Netherlands and during $89.3 \%$ of time in the opposite direction.

However, as indicated in [2], balancing market designs of both countries currently exhibit significant differences. For instance, with respect to the procurement of balancing services, services in Belgium are remunerated relatively more for capacity ( $€ / \mathrm{MW})$ - i.e. reserved beforehand to ensure their availability - compared to the Netherlands. Furthermore, while in Belgium energy payments (€/MWh) - i.e. a remuneration for the balancing power actually delivered - are determined pay-as-bid, they are based on market clearing prices in the Netherlands. With respect to the imbalance settlement, methods of imbalance pricing differ. While imbalance prices in the Netherlands are calculated on the 
basis of a single-pricing system ${ }^{1}$, in which the same imbalance price - be it with a different sign - is applied for remaining short and long positions, Belgian imbalances are settled using a double-pricing system, in which prices are differentiated according to the sign of the imbalance. For instance, in case the net activated balancing volume in the Belgian control area is incremental, the price for a short position is determined on the basis of the total activated incremental balancing power, while the price for a long position is calculated relying on the day-ahead power exchange - i.e. Belpex - price. Further note that, while in the Netherlands the gate closure time equals to 1 hour ahead of real-time, Belgium implemented a day-ahead gate closure combined with the possibility of trading imbalances until one day after delivery. Settlement periods on the contrary amount to $1 / 4$ hour in both countries.

\section{ROADMAP TO IMPLEMENTING CROSS-BORDER BALANCING}

Several approaches with respect to the implementation of cross-border balancing have been put forward so far, each requiring a different degree of market harmonisation and entailing differing potential benefits [3][4][5][6][7]. Proposals include:

\section{- TSO-BSP versus TSO-TSO trading}

While the first approach consists in enabling Balancing Service Providers (BSP) to contract for the provision of balancing services directly with the TSO of the neighbouring control zone, the second one involves the exchange of balancing services between neighbouring TSOs.

\section{- Balancing energy trading}

This approach enables TSOs to procure balancing energy through energy payments - from neighbouring control areas. Exchanges can either be limited to services in excess of those needed to maintain the balance in the TSO's own control area or can include all services via the use of a common merit order. Imbalances of control areas can be cancelled out as far as possible. Potential benefits include the activation of the cheapest available resources as well as a reduction of total energy payments.

\section{- $\quad$ Reserve trading}

This approach enables TSOs to procure reserves - through capacity payments - from neighbouring control areas, bilaterally or via the use of a common merit order. Potential benefits include the procurement of the cheapest resources as well as a reduction of total capacity payments.

- One regional control area

This approach involves joining existing control areas into one global control area, together with a transfer of balance responsibilities to one supervisory body that would be appointed for maintaining a balance at an overall regional level. Potential benefits include a reduction of total required reserve volumes at regional level as resources would be activated for the regional balance only.

\footnotetext{
${ }^{1}$ Note that this single-pricing system is altered for a double-pricing system in settlement periods where balancing power was activated in both directions.
}

The practical implementation of cross-border balancing can take place in gradual stages. In [8], a roadmap is set out that should enable a stepwise and effective implementation of cross-border balancing in Europe. This roadmap comprises the following three consecutive phases:

\section{- PHASE I: Implementation with minimum prerequisites}

The objective of this first phase is to enable cross-border balancing trade quickly - according to the "balancing energy trading” approach above - taking into account only minimum prerequisites. Given that national differences in the remuneration for balancing services - e.g. the relatively higher amount of capacity payments in Belgium compared to the Netherlands - may act as a barrier to exchanging all services via common merit order, limiting cross-border balancing procurement to excess services only is acceptable in this phase. Minimum prerequisites include the harmonisation of technical characteristics of balancing services (e.g. activation time) and gate closure times.

- PHASE II: Harmonisation of remuneration for services As indicated above, national differences in the method for remunerating balancing services may hamper the exchange of services via common merit order in the first phase. More specifically, TSOs reserving relatively more services using capacity payments may be reluctant to exchange their services as they fear 'losing' their reserves, the costs of which are often borne by their own grid users. Thus, to extend the cross-border procurement of balancing services from excess services only to all services - via the use of a common merit order - this second phase includes harmonising the way in which services are remunerated.

\section{- PHASE III: Harmonisation of imbalance settlement}

While the initial phase enables benefiting from cross-border balancing at minimal cost, it does not eliminate distorting effects of insufficiently harmonised imbalance settlements on day-ahead and intra-day trade. For this reason, the initial implementation of cross-border balancing should be further optimised in this final phase.

Independent from the implementation phase, cross-border exchanges should always be subject to grid availability as reservations of interconnection capacity would come at the expense of wholesale trade.

\section{DATA DESCRIPTION AND METHODOLOGY}

The analysis in this paper assumes the implementation of TSO-TSO balancing energy trading with common merit order but without full market harmonisation or, in other words, with fulfillment of minimum prerequisites only, according to PHASE I in the previous Section. Abstraction is made of the fact that one of the countries concerned - i.e. Belgium given its relatively higher amount of capacity payments - might be reluctant to participate in a common merit order without harmonising service remuneration methods.

Calculations are made based on the following data [9] and assumptions:

- The dataset contains data on a $1 / 4$ hour basis, i.e. the settlement period for both countries. The dataset covers 
the year 2008, comprising data from 01/01/2008 up to 26/12/2008 (system imbalance data in the Netherlands are lacking for the period 27-31/12/2008)

- System imbalances of Elia (Belgium) and Tennet (Netherlands):

System imbalances in Belgium are assumed to equal the negative Net Regulation Volume (NRV). NRVs are used to represent the amount of services TSOs had to activate per settlement period. In practice however, TSOs sometimes regulate up- and downward within the same settlement period, implying actual activations - and associated costs - can be different from the NRV. System imbalances in the Netherlands are represented by the volume of settled imbalances.

- Bid volumes and prices of balancing services of Elia and Tennet:

Bid data published by Elia and Tennet are limited to the marginal prices of bids that would be activated for certain predetermined volumes, being +/- $100 \mathrm{MW}$, +/- $300 \mathrm{MW},+/-600 \mathrm{MW}$ and +/- maximum volume (representing the last offer activated). Bid data are based on D-1 submissions. Bids are assumed to be activated based purely on merit order. Balancing Service Providers (BSP) are assumed to exhibit the same bidding behaviour in a cross-border balancing market as in a national balancing market. Arbitrage possibilities - following the cheapest downward bid of a country being higher than the cheapest upward bid - are made abstraction of.

- Available cross-border interconnection capacities:

Due to a lack of cross-border intra-day trade - neither via power exchange or OTC - between Belgium and the Netherlands [10], cross-border capacities available at the day-ahead gate closure (DA GC) are used. Given current intentions to implement a regionally organised intra-day market through the Central West region [11], analyses are also carried out assuming reduced available capacities $(90 \%$ and $10 \%$ of available capacities after day-ahead gate closure respectively). Note that, besides cross-border intra-day trade, capacities available after day-ahead gate closure may not be fully available for cross-border balancing exchanges due to internal constraints, some capacity being kept for security reasons, etc.

For each $1 / 4$ hour considered the following analyses are made:

- Calculation of balancing costs without cross-border balancing - i.e. balancing services are procured in Belgium and the Netherlands separately and netting of opposed imbalances is not allowed

- Calculation of balancing costs with cross-border balancing - i.e. balancing services can be procured cross-border through a common merit order and netting of opposed imbalances is allowed. All netting and cross-border procurement opportunities are verified against the available cross-border capacities.

Focus in the analyses is on global benefits rather than individual country benefits.

\section{RESULTS}

Table I gives an indication of the $\%$ of $1 / 4$ hours in 2008 during which cross-border balancing would have been profitable, i.e. would have entailed cost reductions due to netting and the cross-border procurement of relatively cheaper services. It also illustrates that capacity constraints would have put limitations on cross-border balancing in less than $7 \%$ of $1 / 4$ hours.

\section{Table I: \% of $1 / 4$ hours with cross-border border balancing opportunities}

\begin{tabular}{|l|c|}
\hline $\begin{array}{l}\text { \% of } 1 / 4 \text { hours with total cost reduction potential } \\
\rightarrow \text { assuming unlimited capacity }\end{array}$ & $95.22 \%$ \\
\hline $\begin{array}{l}\% \text { of } 1 / 4 \text { hours with effective total cost reduction } \\
\rightarrow \text { taking into account available capacities after } \\
\text { DA GC }\end{array}$ & $88.38 \%$ \\
\hline
\end{tabular}

Figure 1 and Figure 2 contain an illustration of the benefits cross-border balancing could have entailed during one specific $1 / 4$ hour, i.e. on 30/04/2008 from 7.45 up to $8.00 \mathrm{am}$. During this quarter, Elia was faced with a negative imbalance of almost $120 \mathrm{MWh}$, while Tennet's control area exhibited a positive imbalance of approximately 14 MWh. Available cross-border capacities amounted to $1331 \mathrm{MW}$ from Belgium to the Netherlands and 77.5 MW vice versa.

Figure 1 illustrates the case without cross-border balancing in which both TSOs would have activated bids from their own merit order: Elia would have procured about 120 MWh upward balancing power - implying a total cost of $\pm 8216 €-$ while Tennet would have selected almost 14 MWh of downward bids - implying an income of $\pm 578 €$. Total costs for both countries would consequently have equalized \pm 7638 $€$.

Figure 2 depicts the case with cross-border balancing. Given the opposed direction of system imbalances in both countries, netting could have occurred, implying a flow of almost 14 MWh from the Netherlands to Belgium. The remaining negative imbalance in Belgium could have been solved by activating bids from the common merit order, implying an additional flow of approximately 6 MWh from the Netherlands to Belgium. Total costs for both countries would have amounted to $\pm 6471 €$. In other words, the implementation of cross-border balancing could have resulted in an overall cost reduction of more than $15 \%$. Note that the available cross-border capacity of 77.5 MW from Belgium to the Netherlands did suffice to accommodate all extra flows.

Figure 3 and Figure 4 consider another $1 / 4$ hour, i.e. on 21/02/2008 from 23.45 up to midnight, to illustrate the restrictions capacity constraints may impose on cross-border balancing. During this quarter, Elia was faced with a negative imbalance of more than $60 \mathrm{MWh}$, while Tennet's control area exhibited a positive imbalance of approximately 53 MWh. Available cross-border capacities amounted to 1108 MW from Belgium to the Netherlands and 43.1 MW vice versa. 
Figure 3 illustrates the case without cross-border balancing in which both TSOs would have activated bids from their own merit order: Elia would have procured about $60 \mathrm{MWh}$ upward balancing power - implying a total cost of $\pm 3191 €$ - while Tennet would have selected more than 53 MWh of downward bids - implying an income of $\pm 1542 €$. Total costs for both countries would consequently have equalized $\pm 1649 €$.

Figure 4 depicts the case with cross-border balancing. Given the opposed direction of system imbalances in both countries, netting could have occurred, implying a flow of more than 53 MWh from the Netherlands to Belgium. However, available cross-border capacities did not suffice to accommodate these extra flows. As a result, system imbalances could not have been netted out completely and remaining imbalances would have to be solved through activation of bids within the own control area. Total costs for both countries would have been $\pm 607 €$. In other words, the implementation of cross-border balancing could have resulted in an overall cost reduction of more than $63 \%$. In case cross-border capacities would have been sufficient, total costs would have amounted to only 352 $€$, implying a reduction of $78 \%$. In other words, capacity constraints limited the benefits that could have been reaped through cross-border balancing with $15 \%$.

Table II gives insight into the magnitude of cost reductions and profit increases that could have occurred throughout 2008 as well as the impact of capacity constraints on them.

Cost reductions - i.e. the TSO pays BSPs - are significant; profits - i.e. BSPs pay the TSO - alternately increase or decrease but always to a small extent. Limitations due to cross-border capacity constraints turn out to be rather small. An overall cost reduction of $\pm 37 \%$ could have been made without any investment in cross-border capacity as the available cross-border capacity has already been paid for. The additional flows induced by cross-border balancing predominantly took place from Belgium to the Netherlands. More specifically, $90.16 \%$ of all extra flows were in this direction.

Table II: Cost and income reductions following cross-border balancing between BE and NL in 2008

\begin{tabular}{|c|c|r|r|r|}
\cline { 2 - 5 } \multicolumn{1}{c|}{} & \multicolumn{2}{c|}{$\begin{array}{c}\text { With unlimited } \\
\text { capacity }\end{array}$} & \multicolumn{2}{c|}{$\begin{array}{c}\text { With available } \\
\text { capacity after DA GC }\end{array}$} \\
\cline { 2 - 5 } & Cost $\downarrow$ & Income $\uparrow$ & Cost $\downarrow$ & Income $\uparrow$ \\
\hline JAN & $52.86 \%$ & $1.52 \%$ & $49.23 \%$ & $0.21 \%$ \\
\hline FEB & $50.22 \%$ & $3.26 \%$ & $47.66 \%$ & $2.70 \%$ \\
\hline MAR & $42.74 \%$ & $-3.70 \%$ & $40.88 \%$ & $-2.32 \%$ \\
\hline APR & $36.42 \%$ & $-4.60 \%$ & $33.74 \%$ & $-2.93 \%$ \\
\hline MAY & $56.69 \%$ & $3.64 \%$ & $55.40 \%$ & $3.43 \%$ \\
\hline JUN & $50.76 \%$ & $1.16 \%$ & $47.91 \%$ & $-3.26 \%$ \\
\hline JUL & $40.21 \%$ & $-4.74 \%$ & $36.66 \%$ & $-6.73 \%$ \\
\hline AUG & $58.90 \%$ & $15.15 \%$ & $27.45 \%$ & $2.85 \%$ \\
\hline SEP & $27.26 \%$ & $-5.91 \%$ & $26.19 \%$ & $-6.88 \%$ \\
\hline OKT & $28.30 \%$ & $-2.60 \%$ & $24.12 \%$ & $-1.47 \%$ \\
\hline NOV & $30.52 \%$ & $-2.84 \%$ & $20.70 \%$ & $-2.80 \%$ \\
\hline DEC & $33.13 \%$ & $-4.21 \%$ & $30.56 \%$ & $-3.87 \%$ \\
\hline Total & $\mathbf{4 3 . 6 5 \%}$ & $-\mathbf{1 . 0 9} \%$ & $\mathbf{3 7 . 0 1 \%}$ & $-2.09 \%$ \\
\hline
\end{tabular}

Table III finally illustrates the impact of increasing interconnection capacity reductions - e.g. through the implementation of intra-day trade, internal constraints, capacity being reserved for security purposes, etc. - on effective cost reductions and income increases. While the impact of a small capacity reduction is only minor, significant cross-border balancing opportunities disappear in case only $10 \%$ of “available” capacity after DA GC would be available for the exchange of balancing services.

\section{Table II: Impact of cross-border capacity reductions on cross-border balancing benefits}

\begin{tabular}{|c|c|c|}
\cline { 2 - 3 } \multicolumn{1}{c|}{} & $\begin{array}{c}\text { Cost reduction } \\
\text { (TSO pays BSPs) }\end{array}$ & $\begin{array}{c}\text { Income increase } \\
\text { (BSPs pay TSO) }\end{array}$ \\
\hline $\begin{array}{c}\text { With unlimited } \\
\text { capacity }\end{array}$ & $43.65 \%$ & $-1.09 \%$ \\
\hline $\begin{array}{c}\text { With 100\% of } \\
\text { available capacity } \\
\text { after DA GC }\end{array}$ & $37.01 \%$ & $-2.09 \%$ \\
\hline $\begin{array}{c}\text { With 90\% of } \\
\text { available capacity } \\
\text { after DA GC }\end{array}$ & $36.44 \%$ & $-2.18 \%$ \\
\hline $\begin{array}{c}\text { With 10\% of } \\
\text { available capacity } \\
\text { after DA GC }\end{array}$ & $29.16 \%$ & $-15.34 \%$ \\
\hline
\end{tabular}

\section{CONCLUSIONS}

The presented analyses illustrate that the implementation of a cross-border balancing market between Belgium and the Netherlands is a lucrative and achievable goal that does not entail unrealistic or overly expensive preconditions. Significant cost reductions could have occurred with cross-border balancing during the year 2008 - due to netting and cross-border procurement of relatively cheaper services. Restrictions imposed on cross-border balancing due to cross-border capacity constraints would have been rather small ${ }^{2}$ : capacities available after day-ahead gate closure are far from being fully used so far and given that profitable exchanges in real time can have an opposite direction to those in the day-ahead (and intra-day) stage, more capacity sometimes becomes available in real time due to capacity netting. The implementation of cross-border balancing does consequently not require any network investments. Neither is a full market harmonisation needed.

\section{REFERENCES}

[1] Meeus L. and Belmans R., Electricity market integration in Europe, 16th Power Systems Computation Conference (PSCC), Glasgow, Scotland, July 14-18, 2008, 5 pages.

[2] Vandezande L., Meeus L., Belmans R., The next step in the Central Western European electricity market: cross-border balancing, Revue e tijdschrift, Vol.124, Issue 1, March 2008, pp. 19-24.

\footnotetext{
${ }^{2}$ Note that a well-functioning cross-border market does not necessarily mean that there is always one single market - it can also come down to decentralised integration with different price areas in case of network congestion.
} 
[3] ETSO, Current state of trading tertiary reserves across borders in Europe, November 2005, available at http://www.etso-net.org

[4] ETSO, Key issues in facilitating cross-border trading of tertiary reserves and energy balancing, May 2006, available at http://www.etso-net.org

[5] ETSO, Balance management harmonisation and integration. $4^{\text {th }}$ report, January 2007, all available at http://www.etso-net.org

[6] Frontier Economics and Consentec, on behalf of the European Commission, Benefits and practical steps towards the integration of intraday electricity markets and balancing mechanisms, available at http://ec.europa.eu/energy/index_en.html

[7] ERGEG, Draft Revised ERGEG Guidelines of Good Practice for Electricity Balancing Markets Integration (GGP - EBMI), 15 January 2009, available at http://www.ergeg.org/
[8] Tractebel Engineering and Katholieke Universiteit Leuven, on behalf of the European Commission, Study on interaction and dependencies of Balancing Markets, Intraday Trade and Automatically Activated Reserves, February 2009, available at http://ec.europa.eu/energy/index_en.html

[9] All data used can be found on http://www.elia.be and http://www.tennet.org

[10] ETSO, Current state of intra-day markets in Europe, May 2007, available at www.etso-net.org

[11] APX, Belpex, EEX and Powernext, Cross-border intra-day markets. White paper on a possible market model proposed by APX, Belpex, EEX and Powernext, July 2007, for instance available at http://www.apgroup.com
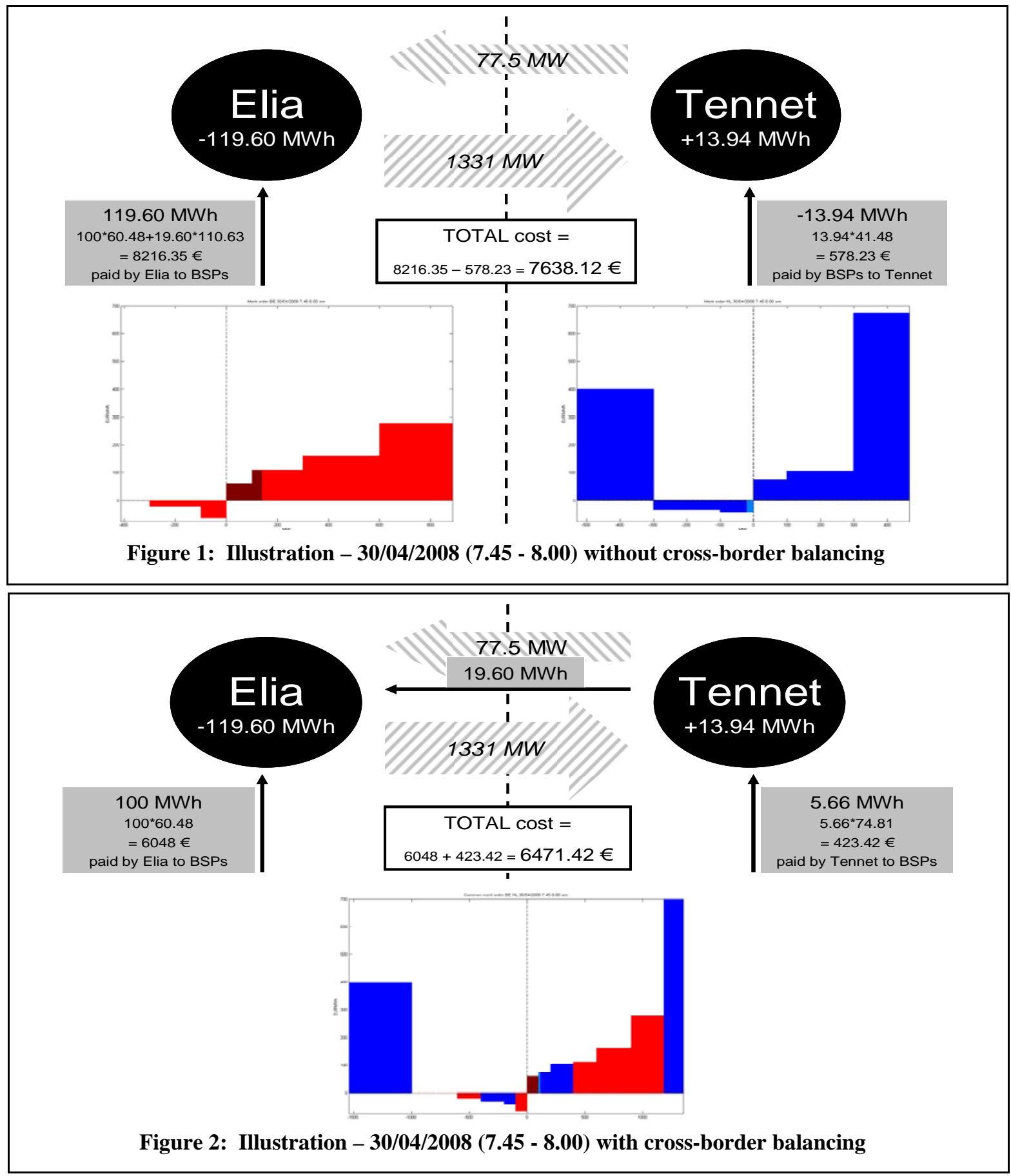

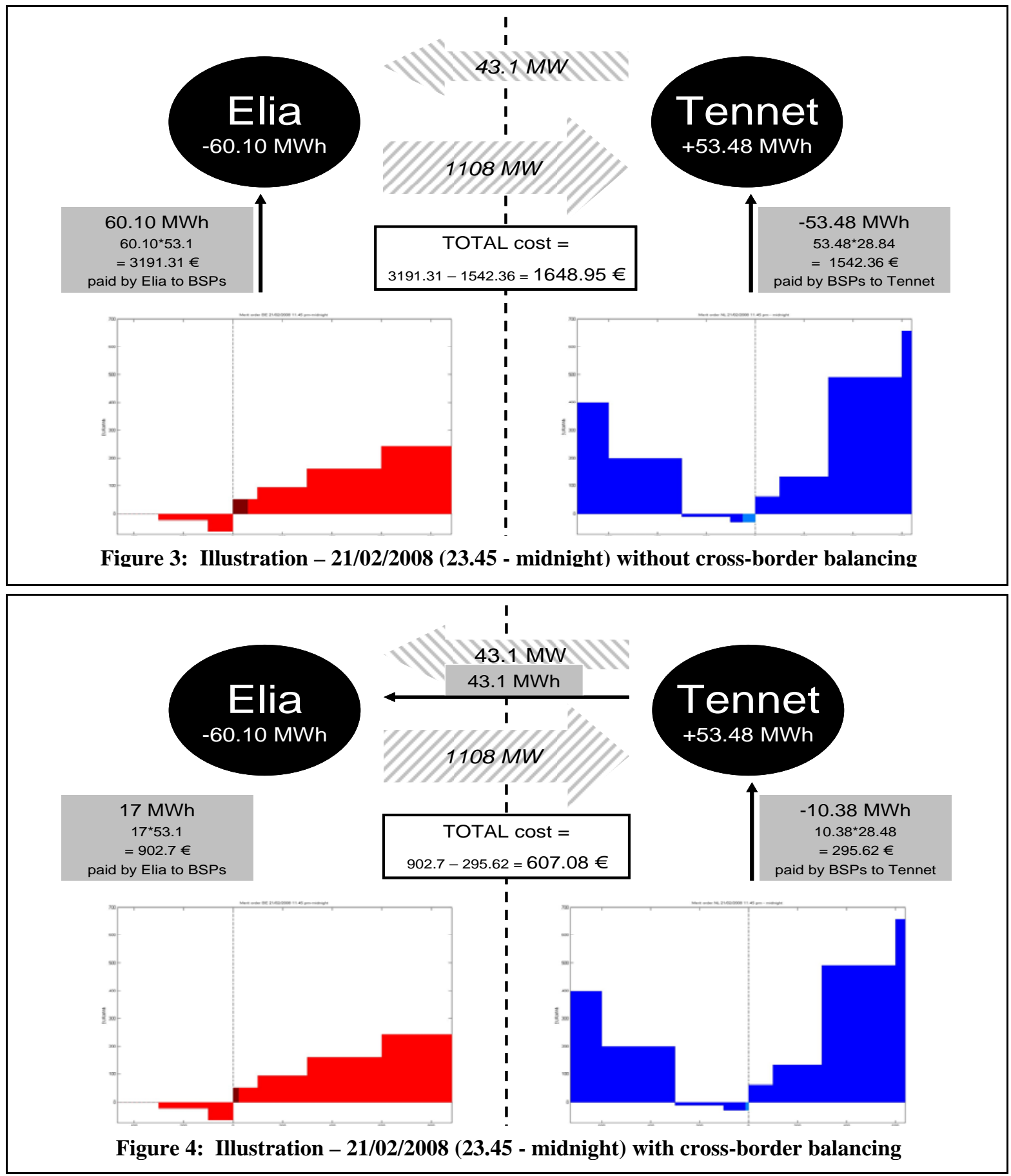